\title{
The Learning Effect of Electroacoustic Music in Secondary Education An Interdisciplinary Practice in Greek Schools
}

\author{
VASSILEIA BOURA \\ Patriarchal University Ecclesiastical Academy of Crete \\ Herakleion, Crete, Greece
}

\begin{abstract}
In the rise of the 21st century, the music educator in modern schools is challenged to educate and train students in both conventional and contemporary music theory and practice. The contemporary approach to music learning and composition requests knowledge and practical skills from interdisciplinary fields. Electronics, physics, mathematics, computer science and music are merged to produce different contemporary styles of music. Students, in secondary education, are challenged to develop listening, performing and computer music skills, to expand their musical aesthetics and culture, together with their musical memory. Music educators are expected to teach a wide range of musical styles and techniques. Science and technology are parts of the musical practice in schools. Music has become an interdisciplinary subject, capable, more today than ever, to educate and shape personalities in school and for preparing students to be strong and healthy for entering society. Scientific and empirical research continues to be conducted to provide helpful guidelines for teachers' intentional use of music, in every class. This paper provides music educators with successful and valuable methods for incorporating electroacoustic music into the teaching and learning school environment applicable to secondary school settings.
\end{abstract}

Keywords:- Electroacoustic music, Learning, Secondary Education.

\section{INTRODUCTION}

Secondary education curriculum in Greece, either for public, private or European school systems, is challenged to apply scientific research theories and methods, to a broader humanitarian and emotional education, that aims to suppress violence, racism and diversity (social, cultural, economical, educational); to promote self-control, concentration, creativity, collaboration, mental health; to promote a positive atmosphere of cooperation between students, parents, school administration, educators and society; to facilitate student inclusion and adaptation by promoting the well-being.

In the modern world of science and technology, with over specialised fields of study, secondary school students aim to increase their specialised experience and knowledge, which will offer them a successful and profitable career. School classes offer students an over-specialised, isolated knowledge that does not contribute to their overall prosperity in spirit, body and soul. The interest of the school and society is for the student to acquire the knowledge per se and not what this knowledge has to offer to the student's personality. From ancient times the educated man was equally educated in body, mind and soul. A healthy mind in a healthy body has been the goal since the time of Hippocrates.

In modern Greek schools, music stragles to regain its mediator's role under which, interdisciplinary learning, interpersonal relationships and prosperity could be promoted. Research has shown that music affects a student's character and values, contributes to conflict solving, helps adjustment and motivation, enhances communication, expression and collaboration, reduces violence by controlling racism and diversity, increases mental functions by improving psychological and physical health (Lazanov, 1960 and Brewer, 1995). Could electroacoustic music also affect students in that way?

In the last decade, an electroacoustic music chapter was added in Greek music books. Music software and hardware are used by students to create either a simple music score, or a complex computer music track. Although the actual learning of how to use the software and hardware is not considered a problem for students, understanding and appreciating electroacoustic music is. Its extraordinary and abstract style, make it unfamiliar and difficult to perceive. Most of the students do not consider electroacoustic music as a musical form at all. They refer to it as "simple noise" and an unbearable one, without melody or rhythm, without meaning, or recollection. Actually, most of the people in the school community consider electroacoustic music as such. So, how can music educators approach electroacoustic music learning and appreciation in schools? Furthermore, how could music educators achieve an electroacoustic music integration into the curriculum in enhancing interdisciplinary learning?

In the context of New School (2011), a revised curriculum of school and social life for Greek schools, empirical educational programmes have been approved for public and European schools in Greece, by the Hellenic Ministry of Education and Religion Affairs. Through the programmes, an effort to reach out to students and the wider school community was made. The aim was to improve learning and social skills in the intra-school community. The programmes referred to in this paper integrated 
electroacoustic music to different classes. Electroacoustic projects and multicultural activities in the context of an integrated education were conducted, along with the school curriculum, to support and extend music class. Collaboration, between educators, students and the school community were planned. Interpersonal relationships expected to be built upon music experience. The effect of electroacoustic music in cognitive, physical, emotional and social skills was observed and analysed. The electroacoustic programmes took place from 2012 to 2016.

\section{EMPIRICAL ELECTROACOUSTIC MUSIC LEARNING METHODS AND ACTIVITIES.}

In these methods and activities, which we refer to in this paper as "integrating," the music educator "helps students understand the connections among the disciplines", emphasising the point made by Einstein that "all disciplines and forms of inquiry are branches from the same tree" (National Academies of Sciences, Engineering, and Medicine, 2018) and familiarise students and school community with electroacoustic music.

The methods applied and the activities performed in these electroacoustic music programmes, were inspired by previous scientific researches on the integration of music in general, in the classes, such as John Hopkin's Study in integrating music in the classroom (Brewer, 1995), the Active Learning Experiences using music in the classroom (Lazarov, 1960), the "Mozart Effect" (Campbell, 2001) and the research on How arts integration supports student learning (DeMoss, K. \& Morris, T., 2002). Counter to previous researches, electroacoustic music was used, not any other orchestral, or contemporary musical style. Extensive reference and bibliography, in Greek and in English, was available to educators and students in each interdisciplinary class relating electroacoustic music to science and humanity studies.

Electroacoustic music was integrated in music and other class curriculums. The programmes' aim was not to devalue the different educational disciplines, which are important for students' expertise, nor to prove the argument that an integrative approach is superior to any other educational method. Rather, the aim was to investigate the effect that an interdisciplinary subject, such as electroacoustic music, would have in students' multidisciplinary learning in school, as well as, the effect of electroacoustic music practice on improving their interpersonal relationships and social skills, improving wellness and prosperity as future citizens. Furthermore, electroacoustic music was introduced to the students and the school society, as a contemporary scientific art form, that would help them expand their musical perception and memory, improve their learning ability and concentration, and reinforce their expression and communication skills. The expected results concerned the effect of electroacoustic music to students' effective multidisciplinary learning, their socialisation, personality and life attitude. The educational programmes included empirical activities on humanitarian and scientific fields.
Electroacoustic music was integrated in class, in different subjects, primarily as a soundtrack music, then, as a creative medium to activate information (mental, physical and emotional) and to express and reflect students' emotions and finally, as an interdisciplinary medium for increasing knowledge, learning motivation and social skills to the students.

All the students who participated in the educational programmes attended the particular school units, were between 12 and 16 years old and came from different cultures, social or economic statuses, had different nationalities, learning difficulties, special needs, or cognitive levels. All students were included without discrimination in the educational programmes.

The programme organiser together with experienced educators, in collaboration with music educators and with music technology expertise, identified an academic unit that they would teach to different classes, for each secondary grade, during the course of the educational programmes. The academic unit was approved by school psychologists, class advisors, school directors, pedagogical and musical advisors. The academic unit incorporated electroacoustic music in teaching practices. Lesson plans, of every class, included electroacoustic music related topics, electroacoustic music three minute breaks, soundtrack electroacoustic music on related topics, one minute silence breaks, evaluation and lesson tests at the end of the class. A qualitative data collection and analyses was used. Students' achievement was measured using standardised achievement test scores. Information about the students' learning processes in the electroacoustic music academic unit was recorded by students' interviews, lesson tests, semester a

ssessments and assignments and penalty recording. We interviewed students before and after class to gather information about motivation and interest changes in a particular topic. Students were also asked to answer questionnaires in order for educators to analyse their responses and assess the effect of electroacoustic music to learning and improving social skills in the electroacoustic music integrated classes, compared to traditional non electroacoustic ones from the past. Class attention, attitude and atmosphere was also observed to understand the interpersonal relationships achieved between educators and students, and between students themselves, during electroacoustic music integrated classes.

In addition several methods for monitoring students' learning effect and social skill improvement were used. Such as: students' mark monitoring between semesters in each subject for a three year secondary education course, discipline/detention records for each student, school psychologist semester reports on school violence, questionnaires that were provided to school director, students, educators and parents/guardians to be answered, concerning the effect of the electroacoustic music learning to the overall student performance during the course of the educational programmes, course and class evaluation sheets were handed to students and educators in order to assess the success of the educational approach and students' amount of 
understanding and recollection on the introduced knowledge.

Additional information, on the effect of electroacoustic music integration in school subjects, were drawn from the participation level of students, educators, parents/guardians and the wider society in all the electroacoustic events, which was measured by ticket selling, newspaper reports, and municipal and private voluntary funding on extra supporting this effort to integrate electroacoustic music to the school society.

No expensive supplies were needed in order to incorporate electroacoustic music into the different classes. $\mathrm{CD}$ players and computer devices were already present, as school supplies ready to be used by any educator. Computer sciences rooms were available to be used by all participated students and educators, as extra computer working stations. Music technology rooms were founded by the local school board and established in both schools involved in the educational programmes. The music technology rooms were equipped by computer stations with wifi connections, sequencers, midi instruments and a mixing console, available for the students to use. Web-based music programmes which were easy to access and had loads of tutorials, as well as, digital audio workstations (DAWs) were available to the students. In addition, several musical instruments (piano, guitar, cretan lyre, lute, mantoline, bouzouki, electric guitar, electric base, drum set, violin, trumpet, flute, clarinet, recorder, synthesiser) were available to the students for practice and recording. Many students were allowed to bring their own musical instruments in the school for the needs of the educational programmes, under the written parents' approval.

Extra precaution measures were taken by the school administration for afterschool programme sessions and activities, and additional written approvals were requested by the parents/guardians.

The selection of the electroacoustic compositions to be incorporated in the different classes was made based on the genre (such as musique concrete, elektronische musik, acousmatic music, electronic music, tape music, algorithmic synthesis), the place and time of composition, as well as its background aesthetics and historical influences. Students were to get acquainted with, as many different types and techniques of electroacoustic music, as possible. The electroacoustic compositions incorporated in the different classes are listed in the appendix of this paper.

In general, the common methods and practices we used to integrate electroacoustic music in most school classes are the following.

- Playing electroacoustic music as background music for class entries, exits and breaks.

- Use electroacoustic music listening for relaxation, or stimulation, or even as an offence behaviour penalty inside, or outside the class, or during detention.
- Use of electroacoustic music throughout the class curriculum increasing music intelligence.

- Observation of the effect of electroacoustic music to students' mood swings in music classes. Students are requested to realise the effect of electroacoustic music to their emotions, behaviour and state of mind and expand their musical memory exercising self-control and selfknowledge.

- Observation of the effect of background electroacoustic music to students' mood swings in different curriculum classes.

- The extra particular methods and practices we used to integrate electroacoustic music in most school classes, are the following.

\section{> Integrating electroacoustic music in the music class.}

The music educator presented the theory and aesthetics of electroacoustic music and introduced in detail the history, aesthetics, compositional techniques, composers, sound sources, computer software and hardware for every electroacoustic music form. A selection of electroacoustic pieces of music (acousmatic, aleatoric, electronic and computer music), were available for students to listen and learn their historical and aesthetic context, in order to recognise and appreciate them. Soundscapes were introduced to students for expanding their musical memory.

Field trips in different sound environments (industrial, natural, domestic, traffic) in order for students to familiarise themselves with the soundscapes of their living environment.

Sound field recordings took place.

Silence exercises inside and outside class were performed.

Sparsely, on different topics of the music curriculum, electroacoustic music learning was connented with other fields of knowledge (physics, computer sciences, mathematics, language, history, sociology, geography).

Establishment of music technology room for multidisciplinary application and noise control reasons. Electroacoustic music concerts, projects, classes and other interdisciplinary activities, as described below, were taking place in a seperate music technology sound insulated room. Web-based music programmes and digital audio workstations (DAWs) were available to the students. Students were introduced to the music technology room. They learnt to work with musical software and hardware to compose music and sound effects. Mixing and editing techniques were also taught. CD production and internet distribution methods were analysed.

Setting up different school bands. Students experiment on creating electroacoustic remixes from several musical genres (pop, rock, ethic, orchestral, rap). Conventional musical forms were combined with abstract sound environments. Projects and concerts were performed during breaks. Musical instruments and computer devices were combined in the concerts. Two hours per week rehearsals 
took place, in different rooms of the school for each band, in after school hours. Students participated pleasantly and constantly.

Small electroacoustic composition and lyrical projects were set on a monthly basis in order to enhance students' expressiveness and to identify talents. In addition, small projects of composing music on short films and animations were set in every semester. Students were working in the music technology room during music classes and had the opportunity to book a computer station to keep on working in after school hours (music technology room booking timetable). The music educator was guiding and supervising while students were working in the music technology room. Students' compositions and film music were annually released on a school funded CD and were kept in the school library for students, educators and parents to borrow. Participations in local and national student music contests and concerts, as well as, in student film festivals were taking place, by individual students, or student bands. Students presented, or performed their electroacoustic music, or film music to the public. Short films and animation films were produced by students in the computer sciences class. Students were afterwards sound designing and composing music on the film.

Music and sound editing and composition for theatrical plays. Students with the supervision of the music educator were working on the soundtrack of a theatrical play. Recorded environmental sounds, sound effects and computer manipulated sounds were used. The theatrical team of students were supervised by the language educator and the computer science educator. The theatrical play was performed in school, or in public.

Participation of students in the ERASMUS programme, by composing and editing music for the programme's trailers. Collaboration with music students from other countries. Joint music, song and dance concerts and contests. Greek music students presented their electroacoustic works.

\section{$>$ Integrating electroacoustic music in art and psychology classes.}

Creativity and reflection soundtrack electroacoustic music was used for students to express themselves through drawing and creative writing. Analysis and discussion of the produced work of arts followed. Recognition of visual, or scripted emotions, discussion and communication between students. Analysis of the different evoked emotions for each student by students themselves, with the help of the school psychologist. Improving students' self awareness, selfesteem, collaboration and communication skills. A selection of different sound sources was made and used as listening material by the school psychologist. Students listened to electroacoustic extracts in a darkening classroom with their eyes shut in order to maximise hearing and concentration. Students' emotional reactions to natural, instrumental and environmental sounds, as well as, noises, were recorded. Electroacoustic compositions were utilised as expression, concentration and creativity reinforcers. A collaborative course of lectures between the music educator and the art and psychology educator.

\section{> Integrating electroacoustic music in philosophy class.}

Music philosophy was introduced to the students. Ancient Greek philosophical approaches on music affecting human prosperity, as well as, music and world structure were analysed (sophists, Plato and Aristotle theories). Ancient music aesthetics were also introduced and compared with present ones. Students were asked to interpret abstract notions by composing abstract sonic events. Electroacoustic music was studied as a human need to imitate nature, at a prehistoric and present level. The circular musical evolution of sound making by humans was studied, beginning with imitating natural sounds, building the first instruments, inventing musical forms and semiology, moving on to complicated musical forms and finally, implementing science and technology to imitate, again, the contemporary noisy and confusing human environment, making electroacoustic sounds. Ancient Greek music was compared with electroacoustic music. A collaborative course of lectures between the music educator and the philosophy educator.

\section{$>$ Integrating electroacoustic music in physical education class.}

Physical exercises, gymnastic exhibitions and events were held with soundtrack electroacoustic music, as well as electroacoustic music relaxation, or stimulation and motion response (dancing, immobility, ten minute siesta). Use of a leap motion controller to produce sounds by students' different body movements. Students were asked to interpret electroacoustic music examples by improvisation choreographies and expressive body movements. Electroacoustic compositions were used to reduce, increase and musically express students' physical activity. A collaborative course of lectures between the music educator and the physical education educator.

$>$ Integrating electroacoustic music in ancient and modern Greek language, literature and poetry classes.

Correlation, evolution and transition from ancient Greek language structure patterns, text rhyme, meter, rhythm and intonation, to electroacoustic sound context, pitch, rhythm and dynamics. Electroacoustic music was used to interpret and represent in sound, a literature text, or a poem, in a programmatic music way. Electroacoustic music was composed, or used as a soundtrack music on a poem or literature text. Poems and literature texts were recorded and sound manipulated to form a literature electroacoustic composition, implementing characters, settings, conflicts, and resolutions, tempos, and dynamics using natural, instrumental and environmental sound sources. Electroacoustic music was analysed as a music discourse (Boura, 2007) with a specific content and context. A collaborative course of lectures between the music educator and the literature educator. 


\section{$>$ Integrating electroacoustic music in religion/ethics class.}

Tracing the evolutionary and inextricable link between music and religious worship. The important role of religion to the musical evolution from the Apollonian mystical songs, through Byzantine music and Gregorian chant to the contemporary Western musical forms. Exploring musical origins and expressiveness in different ecchlesiastical musical styles worldwide. Issues of music ethics were introduced to the students. Electroacoustic remixes of ecclisiastical chants and hymns were produced by the students in the music technology room. Students were asked to locate ecchleciastical elements and origins of music and lyrics in electroacoustic forms and styles. A collaborative course of lectures between the music educator and the religion/ethics educator with musical examples and ecchleciastical hymns.

\section{$>$ Integrating electroacoustic music in history, geography and sociology classes.}

Interculturalism in musical evolution. Collaborative classes that introduced and analysed to students the simultaneous effect of the geographical shape, the cultural history and the socio-economic conditions that affect the musical styling and evolution in different countries all over the world. Different topics were analysed, such as: The impact of the geographical location and the socio-political conditions of a country or county on its musical culture. Differences and similarities between different musical cultures worldwide. Cultural exchanges and fusions. How the fall of Byzantium in 1453 triggered the export of cultural elements of Ancient Greece and the Byzantine era to Europe. How cultural elements transfered from Europe and Africa to the New World after 1492 and structured the contemporary music of the modern world.

The temperament and the experiences of people pass on to their music and shape their culture. So, knowing the music of a people, we can draw conclusions about its history, its values and its culture. Electroacoustic compositions were introduced and analysed in the history, geography and sociology classes. The historical and aesthetic background of each composition was related to the specific characteristics of the geographical place, the time and socio-political conditions of the time it was composed. Worldwide influences were analytically discussed for each electroacoustic composition. An effort to locate similarities in context and content, between composers of the same country, era and musical genre, was made. Early electroacoustic compositions, from the beginning of the 20th century, were analysed (see Appendix). Acousmatic works vs electronic works in Paris and Germany after World War II. The ways and means of electroacoustic music spread and evolved in America after 1950. A collaborative course of lectures between the music educator and the history, geography and sociology educator. The physical education educator helped also, with the dance learning and presentation of the final public intercultural electroacoustic music performances.
$>$ Integrating electroacoustic music in English language class.

English, as a first foreign language, is a compulsory subject in greek public secondary schools. Electroacoustic music terminology was introduced to the students, in order for them to be able to use the computer software for manipulating sound, composing and editing music in the music technology room. In addition, students were willing to read and understand extra research papers and bibliography on electroacoustic music, in english. A collaborative course of lectures between the music educator and the english educator.

\section{> Integrating electroacoustic music in mathematics class.}

Exploring and analysing different mathematical methods, such as algorithmic, in composing electroacoustic music, with musical examples and new notational practices, p.g. graphic music scores. The abstract mathematical concepts can be visual and audio representations of electroacoustic sounds as fractions, patterns, pitch and ratios. Twelve note system, total serialism, music set theory, three note geometrical symmetries, duration series, time point sets, punctualism, group composition, variable form, stochastic music, aleatorism, chance composition and process music were introduced to the students. Several electroacoustic compositions were analysed, in form and technique, investigating mathematical analogies, equations and algorithms. Algorithmic and electronic music was composed by students in collaboration with the computer sciences class, in the music technology and computer science room of the school. A collaborative course of lectures between the music educator and the maths educator.

\section{$>$ Integrating electroacoustic music in physics class.}

Several electroacoustic music fasmatographs and sound waves were observed and analysed, exploring the theory of soundwaves, the characteristics and the properties of the sound. Students experienced and learned about the effects of sound manipulation to pitch, time, timbre and dynamics. Observing sound waves and their fasmatography in time, and reading electronic scores students applied their knowledge in physics and computer sciences in music, to manipulate different sound sources and eventually compose electroacoustic music. Electroacoustic keys and graphic scores were also produced on students' compositions. A collaborative course of lectures between the music educator and the physics educator.

\section{$>$ Integrating electroacoustic music in computer sciences class.}

Computer music software and hardware teaching. Introducing students to the contemporary scientific approach to composing music in the 21 st century, with the selfevident and imperative use of computers. In addition, sound manipulation, sound editing and mixing techniques in different musical software and hardware were introduced to the students. Electroacoustic music compositions were produced by all students. A collaborative course of lectures between the music educator and the computer sciences educator. 
> Integrating electroacoustic music in biology class.

Indicative approach on human neuroscience and biology research about the effect of music (harmonic sound and noise) on brain and body functions and produced emotions. Students were introduced to the basic behavioral and cognitive theories. They got acquainted with the fact that their biological evolution stages affect their psychoemotional maturation, and vice versa. The limited research on the effect of electroacoustic music to human neurobiology motivated students for future research and career direction. A collaborative course of lectures between the music educator, the biology and the psychology educator.

Electroacoustic music that was composed by students during the educational programmes falls under intellectual property regulations and has not been copyright licenced yet, so it cannot be presented in this paper.

\section{RESULTS AND DISCUSSION}

During the course of all electroacoustic music empirical cultural-educational programmes, of this paper, electroacoustic music pieces from many composers were selected to be listened and analysed by students. The Ministry of Education and Religion Affairs supportive material for the music class was used extensively. A vast list of electroacoustic composers and researchers have been introduced to the students for their work and contribution towards electroacoustic music evolution (see Appendix). In addition, a lot of musical libraries were introduced to the students to use and experiment with sound manipulation using different music software. Different ages of students, between 12 and 16 years old, were allowed to use the school's music technology room, as well as, to participate in the different electroacoustic bands of the school to produce their own music. The programmes' deliverables included hundreds of electroacoustic compositions that were composed by students themselves in the music technology room. CDs with students' electroacoustic compositions available for everyone to borrow in the school libraries. Open access electroacoustic music online playlists and sound libraries were available for educators and students to use in the class. Electroacoustic music playlists, as well as, sound libraries were created and were available for future educators and students to use. CD production and distribution of students' electroacoustic compositions, was also part of the educational music programmes deliverables. In addition, lesson plans integrating electroacoustic music to every class were created. Small essays, school newspaper articles, electroacoustic music installations, paintings and poems/texts on electroacoustic music, electroacoustic compositions on paintings and poems/texts, electroacoustic music performances in school and in public, local radio and TV shows were also parts of the deliverables of the educational programmes.

At the same time, a vast scientific literacy was taken under consideration, in investigating and evaluating students' learning and emotional skills progress, during the course of the educational programmes. After considering multiple forms of evidence (interviews, questionnaire, tests and assessment/evaluation papers) and statistically analysing them, the programme supervisor together with the educators involved in the educational programmes found that certain approaches to the integration of electroacoustic music in science, technology, mathematics, humanity studies and art was associated with positive student learning and personal interrelations outcomes. These included, among others, listening skills, written and oral communication skills, musical composition skills, music performance skills, teamwork skills, content mastery, enjoyment of learning, expression, self-esteem and selfconfidence, productivity and creativity, imagination and recollection. Several different pedagogical approaches (such as project-based learning, lecture, living-learning community) of diverse integration had been applied to the class curriculum, as co-curricular activities. Collaboration between music educators and general/special education educators was succeeded.

Programmes' interviews and evaluation paper results were compared with previous school evaluation papers on students' learning efficiency and school life, retrieved from the school's archive. School evaluations are conducted every two years. The results of the integration of electroacoustic music in the classroom, which are presented in this paper, have been measured based on the deviance between the preprogrammes' and the post-programmes' evaluation papers. Additional results, on the effectiveness of electroacoustic music teaching in school, were drawn from the participation level of educators, parents/guardians and society in all the electroacoustic events. The subject of electroacoustic music was considered innovative, interesting and professionally accessible for students. Eventually, parents/guardians gladly accepted the invitation to participate in events that made their children happy, creative and socially active, supporting them. The enthusiasm of students was well received by local bodies and authorities, which strongly supported every student effort for public presentation and performance. The city community responded positively as well. After the completion of the educational music programmes there were still students and school community people, who, although they had learned to appreciate the electroacoustic musical form, their aesthetical opinion towards electroacoustic music remained biased.

All the students who participated in the educational programmes confronted the concept of electroacoustic music at a very high level of knowledge historically, aesthetically and technically. In all classes electroacoustic music was used as a relevant topic soundtrack music succeeding to increase students' interest, concentration and memory on the introduced knowledge. In general, attention was increased by listening to soundtrack music that was new and innovative to students' ears. They started to be more interested in what the educator had to say, adapting a more quiet and concentrated attitude in the class. Nevertheless, an extensive play, usually more than a total of 10 minutes, of electroacoustic music in the class, had the exact opposite results. Students seemed annoyed and distracted by the abstract noises and mental fatigue followed. Students began to murmur and moan interrupting the flow of the lesson. 
In music class, the analysis of the results of students' general interviews and questionnaires showed the following. The percentages refer to the amount of students with positive answers. Through electroacoustic music and all the means of its analysis and production in the music technology room, students learned to appreciate and recognize the various types of contemporary music $(63 \%)$, the important contemporary and early composers (57\%), the modern methods and techniques of computer music recording (87\%), editing and production (73\%). They expanded their musical repertoire $(89 \%)$ and improved their listening skills to recognise (85\%), understand (64\%) and aesthetically accept (39\%) abstract sound environments, improving and expanding their musical memory (by 36\%). All of them carefully observed and listened to different soundscapes and environmental sounds around them. They learned to describe verbally sonic events (57\%). They realised the difference in frequency, intensity and timbre between listening to a sound very closely and from a distance $(94 \%)$. They noticed new sounds in their living environment, that they had never heard before (86\%). Through the process of field recording and field sound tracking students realised that their acoustic world is much more richer and wider than they thought, and that there are far more sound sources than they consciously knew and heard to that point $(83 \%)$. In several interviews, students argued that their observation and imagination ability increased (by $35 \%$ ), they paid attention and appreciated in depth their personal existence in space (by 45\%), but also the existence and contribution of all living beings and objects in their everyday sound environment (84\%). They began to appreciate and care about their acoustic environment (soundscapes) (59\%), limiting unnecessary noises $(28 \%)$, or amplifying sounds by being silent $(17 \%)$. They appreciated the value of silence in realising the world around them (82\%). They consciously appreciated the meaning of noise pollution $(86 \%)$ and realised how sound (harmonic or noise) can affect their psychology and mood $(89 \%)$, and even their cognitive ability $(38 \%)$ and creativity $(78 \%)$.

The establishment of the music technology room in terms of the educational programmes, took students by surprise. There were students $(64 \%)$ that were already familiar with music technology software who were really happy with the fact that they would actually have access to professional software and hardware with the supervision and guidance of an expert on the field educator, in school. There were also students that, although had no previous experience or knowledge in music technology (36\%), they were happy to find out that their school was evolving to be a modern, up to date educational institute, that would offer them much more contemporary opportunities of learning and career orientations. As a result, all of the students gladly participated in all the educational and creative activities that took place in the music technology room with great outcomes (electroacoustic presentations, electroacoustic compositions, electroacoustic soundtracks, electroacoustic concerts). Students, by experimenting with multicultural fusion and creation, they produced innovative styles of electroacoustic music which they called electro-folk, electro-pop, electro-rock, electro-jazz and so on.

The results from the students' interviews and questionnaires, as well as, the semesters' mark reports showed that their study of electroacoustic music had an increase in their knowledge of music history (by 55\%), of music aesthetics (by 84\%) and of theory of music (by $43 \%$ ). Students, realising the effect of electroacoustic techniques in other contemporary styles of music, that were already familiar with, helped them expand their listening skills (by $76 \%$ ), music practice (by 24\%) and carrier orientation (by $27 \%$ ). By engaging students to be creative through music technology, more and more of them started to study and experiment with sound manipulation techniques, recovering hidden talents of them and pursuing alternative interesting and profitable curriers. Many parents visited school to congratulate the administration and the music educator for giving their children new light in currier orientation.

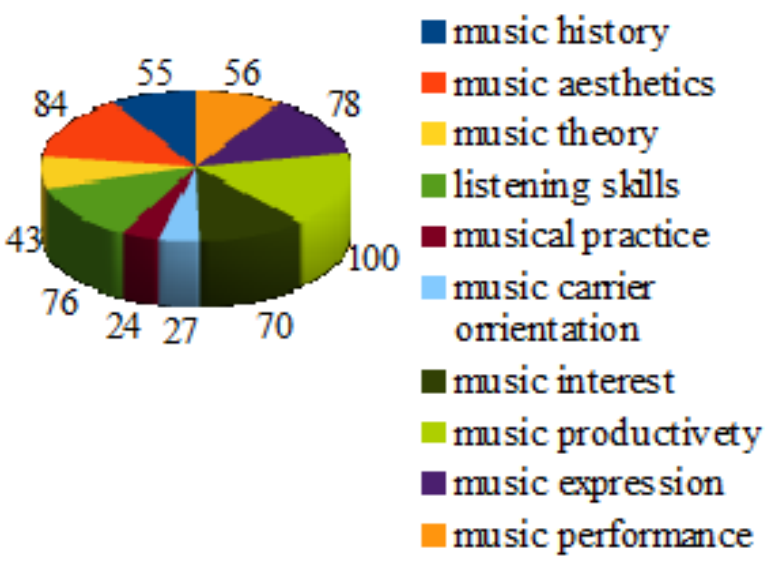

Fig 1:- Increase in percentage (\%) of students' musical skills.

During the educational programmes, a great increase in music intelligence of students was observed, as they learned in detail and in a multidisciplinary way the characteristics and the properties of sound and how to manipulate them. Analysis of the results of students' interviews, questionnaires, tests and assessment/evaluation papers, showed (figure 1) that musical interest increased by $70 \%$ in the music class. Music productivity increased by $100 \%$, as there was none previously. Musical expression increased by $78 \%$, as $45 \%$ of the students found it easier to express themselves musically than verbally $(33 \%)$, or through art $(12 \%)$, or even through creative writing $(10 \%)$. But even for students that musical expression was not their primary choice, to express themselves musically using computer technology was their second choice (20\%). Musical performance increased by $56 \%$. Musical success increased by $67 \%$. Furthermore, students' ability to understand musical meaning and express themselves in music terminology increased by $85 \%$. Science and humanities classes helped students understand meanings and notions related to musical sound, its composition, its use and effect in human life and art. Concentration and effectiveness, working and creating music in frond of a computer increased greatly $(83 \%)$, as students responded to 
questionnaires that: a) a computer workstation and a specific given project helped them concentrate inormusly and be productive and effective b) creating music, remixing it and performing it through computer was appealing and indriging to them, c) computer music skills were more easy to access and acquire than musical instrument performance and composing skills. In addition, recollection of english terminology on computer music knowledge was not an issue for most of the students, as $79 \%$ of them answered that they had familiarised themselves with similar terminology by using different computer programmes and games at home, in the past.

Different types of learning occasionally allowed or not students to use electroacoustic music in the learning process. Listening to electroacoustic music couldn't be imposed in the different classes for all students, because for others it would be helpful while for others it would be divisive. However, in the educational programmes of this paper, we adopted a circular teaching method that, along with other teaching methods, included listening to electroacoustic music periodically during the lesson. The circular teaching method covered all the learning types of students in the classroom periodically. Even students with learning disabilities, according to educators' reports, felt included in the lesson activities and were involved greatly with group projects, increasing, according to the school psychologist, their self esteem, creativity and sociability. $10 \%$ of school students were diagnosed with dyslexia, asperger syndrome and Attention Deficit Hyperactivity Disorder (ADHD). The collaboration between the music educator and the special education educator, for each and every student, provided the opportunity for them to participate and be creative in the educational programmes. In most cases those were the most creative and productive students, as they found a medium of expression, other than verbal, vivid in technology and liberty, without judgment and corrections. Most of these students spent several hours in front of computer workstations to create electroacoustic music. School psychologist's reports pointed out the great effect, working in groups and with computers, had on those students, for their concentration, productivity and sociability.

On the contrary, electroacoustic music negatively affected students with asperger's syndrome in the classroom, as the intense dynamics and high frequencies of several pieces disturbed them. The rest of the students were also annoyed and disturbed by prolonged listening (usually over 10 minutes) of intense dynamics and high frequency electroacoustic music extracts, as previously mentioned. School psychologists reported that all students with dyslexia expressed extraversion and creativity through electroacoustic music, as they participated in public events and created music, without having to express themselves verbally, or in writing.

The effect of integrating electroacoustic music in science and humanities classes was great for these related disciplines, as well. Electroacoustic music highlighted and strengthened the multidisciplinary and interdisciplinary application of music in school learning and training, as previous scientific researches have proven for other styles of music integration (baroque, classical). The integration of electroacoustic music to language, maths, physics, computer sciences, biology, geography, history, sociology, psychology, philosophy, religion/ethics, gymnastics and art classes gave the opportunity to students to connect the different fields of knowledge, to find a meaning and a purpose of studying in all the different discipline curriculums in school, that were occasionally indifferent and pointless for their life. Educators' reports from class evaluation papers showed that students engaging with the educational programmes' interdisciplinary activities increased their learning motivation on connected discipline areas (by 46\%), their understanding on related meanings and notions (by 68\%), improved their multiple learning intelligences (by 41\%), their ability of expressing notions verbally and musically describing and composing sounds (by 56\%), their memory and recollection (by 47\%) (figure 2).

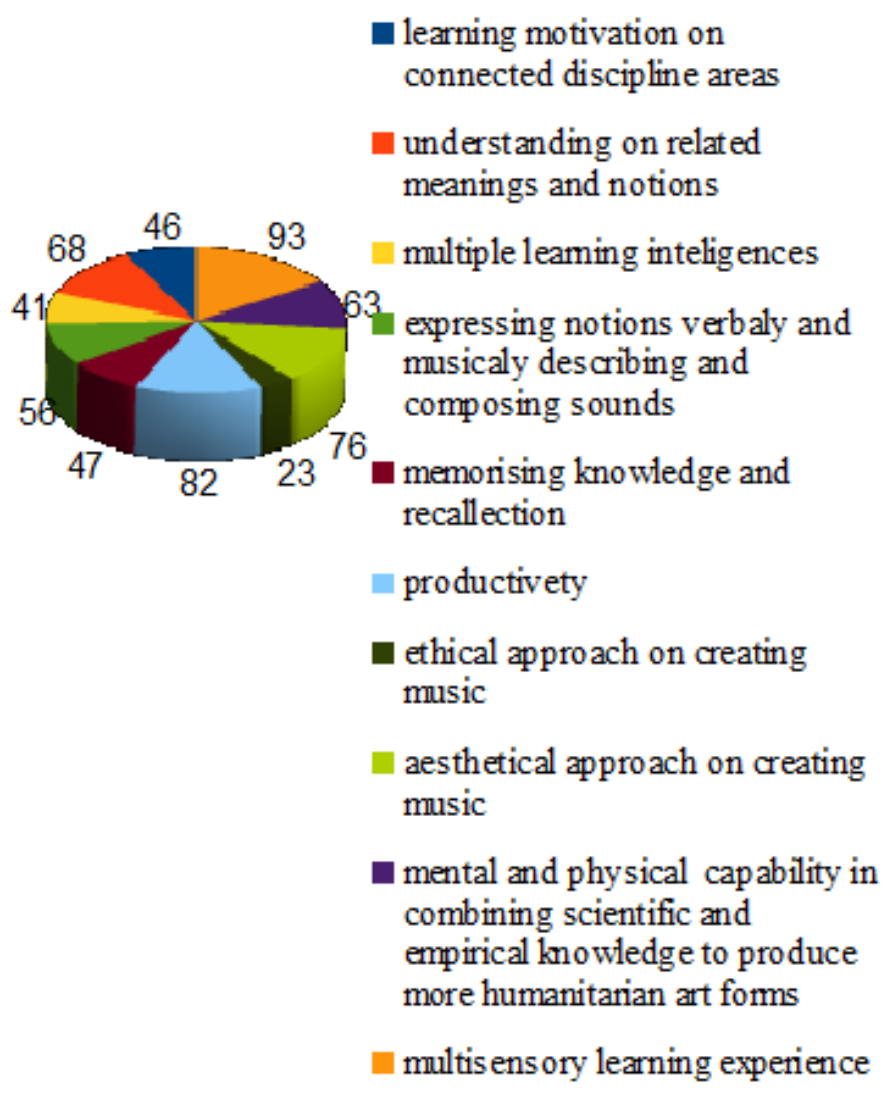

Fig 2:- Increase in percentage (\%) of students' learning skills by the electroacoustic music integration in science and humanities class (educators' reports).

Electroacoustic music motivated and inspired students to approach different disciplines of study in a more creative, empirical and interesting way for improving their wider knowledge. Electroacoustic music helped students learn interdisciplinary information, activating their learning experience and enhancing their understanding of learning. $44 \%$ of the students responded, in interviews and questionnaires, that selected electroacoustic soundtracks improved their focus and deep concentration levels during 
content information learning, processing and memorisation. Students answered positively that performing and composing electroacoustic music by incorporating all the relevant scientific and humanitarian knowledge, from the interdisciplinary integration of electroacoustic music, increased their productivity $(82 \%)$, improved their ethical (23\%) and aesthetical (76\%) approach on creating music, expanded their mental and physical capability in combining scientific and empirical knowledge to produce more humanitarian art forms $(63 \%)$ and facilitated a multisensory learning experience (93\%) (figure 2).

Greek language educator reports and questionnaire results refer to a substantial increase in students' interest (by $85 \%$ ), participation (by $76 \%$ ), creativity (by $68 \%$ ) and greek language marks (by 43\%), by incorporating electroacoustic music teaching practices in Greek language lessons. Students verbally interpreted and represented soundscapes and noises producing inspired literature texts and poems. In addition students wrote lyrics on a given sonic or rhythmic event, improving their verbal skills in vocabulary, rhyme, text meter, intonation and use of dynamics. Language educators reported that the ancient Greek connection between language and music discourse was revived by incorporating electroacoustic music in Greek language classes. Furthermore, language educators reported that students could understand and get better involved with the language information, when electroacoustic music was set as a soundtrack on a poem or literature text analysis. Theatrical plays and musical compositions were performed by students who were implementing characters, settings and resolutions, tempos and dynamics with electroacoustic sound.

English language educators reported that, according to test results, computer music terminology improved the first foreign language knowledge and skills of the students, in terms of vocabulary, by $39 \%$. Furthermore, students were benefited by the extended reading of scientific articles on electroacoustic music and music technology.

Philosophy educators reported that, results of extended interviews and lesson tests in philosophy, showed an increase of students' ability to understand philosophical ideas and notions by $30 \%$. Interpreting abstract ideas and notions with composing abstract sonic events, $75 \%$ of the students reported that they acquired a deep knowledge of how philosophy and aesthetics affect their artistic expression, as well as, their intellectual and mental capacity breadth. On an intellectual level they claimed to realise the connection between philosophy, ethics and music creation. Several open rhetorical debates on subjects related to philosophy and music aesthetics took place during the educational programmes. Great arguments arose among students of different grades, who freely expressed themselves and supported their views with scientific evidence provided either previously in the classroom, or retrieved from the students' research. Essays and small articles on music aesthetics were published in the school's newspaper by several students. Several electroacoustic compositions, incorporating abstract philosophical ideas, were composed by students. For example, students interpreted with sound their understanding of liberty and love, composing electroacoustic compositions in the music technology room.

Religious educators reported an extended increase in students' interest and class participation by integrating electroacoustic music in the class. The deliberate connection between religious worship and musical evolution provoked great discussions among students from different doctrines and religions. Almost $40 \%$ of the students in each class were of different doctrines and religious than the state official Christian Greek Orthodox religion. Students were grouped in debate teams to support different opinions and perspectives on ecclesiastic musical styles and their origins. Lesson evaluation tests by students showed that $77 \%$ of them believed that their beliefs and understanding of the role that religion has in music evolution have expanded. Ethical matters of electroacoustic music expression and composition arose. Religious and ethical questions were analysed. Students wrote essays and small articles that were published in the school's newspaper.

History, geography and sociology classes, gave the opportunity to students to realise that music evolution is an intercultural, timeless procedure. Students were searching for the origins of electroacoustic music in different eras and countries. They presented evidence of historical, geographical and sociological effects on electroacoustic music evolution that were presented on a paper in the school's newspaper. They tried to locate socio-economic and cultural elements in several electroacoustic compositions of early and contemporary composers from all over the world. They produced intercultural performances of music and dancing incorporating electroacoustic compositional techniques in multicultural music remixes. Traditionalising electroacoustic music in the performances included traditional costumes for students and electroacoustic remixes of traditional dances, from different countries. The multicultural electroacoustic performances were a spectacular event that educators, students, and parents enjoyed. The results of the interviews and evaluation papers after the performance, by students, educators and the audience, showed that everyone considered the performances unique in their kind (92\%), interesting (89\%), productive for students and educators $(98 \%)$, educational and pedagogical valuable $(74 \%)$. Through multicultural performances, a way was found to introduce the school community to electroacoustic music for the first time.

Physical education educators greatly supported the performances by familiarising students with electroacoustic music. Students were introduced to reflective motion, dancing, exercising, as well as, relaxing with electroacoustic sounds during the class. They produced modern choreographies which they performed during break times in school. An electroacoustic dance group was formed and a large number of students registered to participate in rehearsals and performances, representing their school in regional dance competitions. Several electroacoustic music and dancing flash mobs were performed in Heraklion city 
centre. The public's response was great. Students interest in electroacoustic gymnastics, according to educator's evaluation tests and interviews, was increased by $47 \%$. $64 \%$ of electroacoustic dance students reported that their improvisation skills and their ability to express themselves physically increased significantly. In addition, all the students stated that the innovative means of movement and music production (leap motion controller), which they did not know before, were introduced to them and were well received and implemented, increasing their interest and motivation for the class.

Biology, physics, mathematics and computer sciences educators, reported that, according to interviews and evaluation tests of the students, incorporating electroacoustic music in their class increased interest and motivation substantially. $21 \%$ of the students showed a career orientation towards mechanical acoustics, in physics class, while $33 \%$ of the students were intrigued by neurosciences and mental effects of music, in biology class. Computer sciences educator reported that incorporating electroacoustic sound manipulation techniques in his class, improved students' computer skills (by 67\%) and marks (by $45 \%$ ). All of the science educators reported a great increase in class attention and participation. Students were eager to undertake and present homeworks related to scientific issues of electroacoustic music. Assignments and homeworks were promptly submitted by $95 \%$ of the students, in contrast to previous submissions that were delayed, or missed. A large amount of electroacoustic compositions with graphic scores were produced by students. Students were allowed to use simultaneously the computer room, the physics room, the music technology room and the biological lab of the school for the needs of their assignments and homeworks. Educators were supervising and helping through the multidisciplinary learning procedure. Students, on their own initiative, created study groups incorporating different scientific subjects to electroacoustic music. They named themselves as "music biologists", "music physicists", "music mathematicians" and "computer music engineers". They were studying together in the school library in after school hours and they were producing small essays on different subjects related to electroacoustic music. Then groups exchanged essays and evaluated each other's works. Corrections were made and the final essay was submitted to the respective science educator for the final mark and to be published in the school's newspaper. Students' interviews and tests results showed an increased level of interdisciplinary and multidisciplinary knowledge. $75 \%$ of the students, apart from the fun of the learning procedure, claimed that they acquired scientific knowledge in an easier and deeper way, by working and researching in groups, than individually, on a subject. Furthermore, they claimed that their recollection on different scientific issues was increased. Unannounced tests in biology, maths, physics and computer science proved an increase of students' course performance by $35 \%$.
Art educators pointed out that abstract electroacoustic soundtrack sounds helped students express themselves in creating abstract and surrealist drawings. Vice versa, by carefully observing an abstract painting, students were composing electroacoustic music on the painting. $56 \%$ of the students claimed to have been more inspired in producing modern art, by listening to electroacoustic music. Sound installations on corresponding paintings were periodically set up in the schools' concert halls during the educational programmes, for students, educators and parents to watch.

The school psychologist was in constant collaboration with all educators and myself as a programme organiser and supervisor, to standardise tests and interviews, as well as, to psychologically assess the outcomes. Students' emotions and attitude were seriously pre-considered and post-considered for every undertaken action.

The conclusions reached by the educators' assembly, on the cognitive results of the educational programmes, were focused on the fact that the more students experienced electroacoustic music the more they learned about it, developing their musical skills, but also, improving their everyday life. In addition, students through the educational programmes, found the meaning and connection of multidisciplinary knowledge to everyday life, as a vivid learning procedure with real life application, rather than a rote memorisation of useless information. Furthermore, interdisciplinary knowledge application to different creative activities helped students communicate academic knowledge with each other and to audiences, strengthening their self-confidence and self-esteem and creating relationships based on respect and communication.

Furthermore, observations on students' attitude showed that at the beginning of the educational programmes, background electroacoustic music during classes and breaks, once a day, had a great effect in students' draw of attention. Due to the diversity, disturbance and peculiarity of electroacoustic music, students tended to stop any other activity in progress, to realise what they were listening to. Silence usually followed. If the music was really noisy, that is, if the electroacoustic composition was completely abstract with no recognisable sound source, then after a few minutes students started to discuss it, even complaining for annoyance. The basic discussion issue in the class and in the school yard among students was about understanding what was the school's loudspeaker playing. Any other activity was seased. Violence, running, scrimming, even going to the bathroom, were diminished, or ceased for as long as the music played. By the time that electroacoustic music became familiar to the students via the educational programmes, background electroacoustic music in the class and during breaks became more of an expected experience and school practice. Based on questionnaire results, almost $67 \%$ of the students expected to hear a new interesting and complicated succession of sound environments, in a random break time, during the school day, and then to discuss the listening experience with the schoolmates, or with the educators in duty, or even with the music educator who they 
were looking for intentionally. Whether they liked the music or not, students critically analysed and appreciated the musical extract, either in class, expressing their opinions in front of their educator and classmates, or during breaks creating small discussion groups of students and educators. Electroacoustic music extracts with extreme dynamics and frequencies (characterised by most students as "annoying") was sometimes used by the school administration as an offence behaviour penalty mostly during breaks. When the students heard the "annoying sounds" they were looking at each other, trying to figure out who had done something wrong and what was that, applying a self -restraint and selfcorrection attitude, or having other students to restrain and correct them. Questionnaire results pointed out that almost $84 \%$ of the students approved and applauded the method of annoying sound penalty, as they felt that school overwatched and cared about students and the problems they were facing during breaks or classes caused by their classmates. In addition to that, school detention book records showed a reduction of $45 \%$ in detension penalties on students with delinquent behavior during the educational programmes.

At the same time, small electroacoustic concerts, during break, or lunchtime, were established with great response and participation by many students. Questionnaire results pointed out that almost $78 \%$ of the students prefered, as more interesting and fun, to attend a concert and watch their classmates play any kind of music, rather than stay in the boring school yard during breaks. Field trips to many different places for sound recording, were also well received by $90 \%$ of the students and parents, as educational and great outdoor experiences.

Evaluation papers and questionnaires, completed by educators, pointed out the effect of electroacoustic music integration to different learning factors (figure 2). Evaluation papers and questionnaires, completed by music educators, pointed out the effect of electroacoustic music in students' musical skills (figure 1). Electroacoustic music activities were used as a vehicle to improve students' learning skills in multiple subjects. Nevertheless, more systematic scientific research and analysis in the future would prove what educational programmes' outcomes, from empirical activities, conclude in this paper.

Students' answers on final interviews, evaluation tests and questionnaires, concerning the effect of electroacoustic music on their learning skills during the course of educational programmes, showed the percentages of students who replied positively in questions related to the increase of: student curiosity on an electroacoustic related topic (90\%), inspired to learn a musical instrument (35\%), inspired to compose electroacoustic music (49\%), vivid/creative class environment $(95 \%)$, establish a positive learning state $(92 \%)$, focus/concentration/attention levels (43\%), build a sense of anticipation (90\%), improve retention and memory $(86 \%)$, facilitate a multisensory learning experience $(92 \%)$, align groups $(89 \%)$, provide motivation $(75 \%)$, effectiveness $(64 \%)$, creating writing or journaling $(68 \%)$.

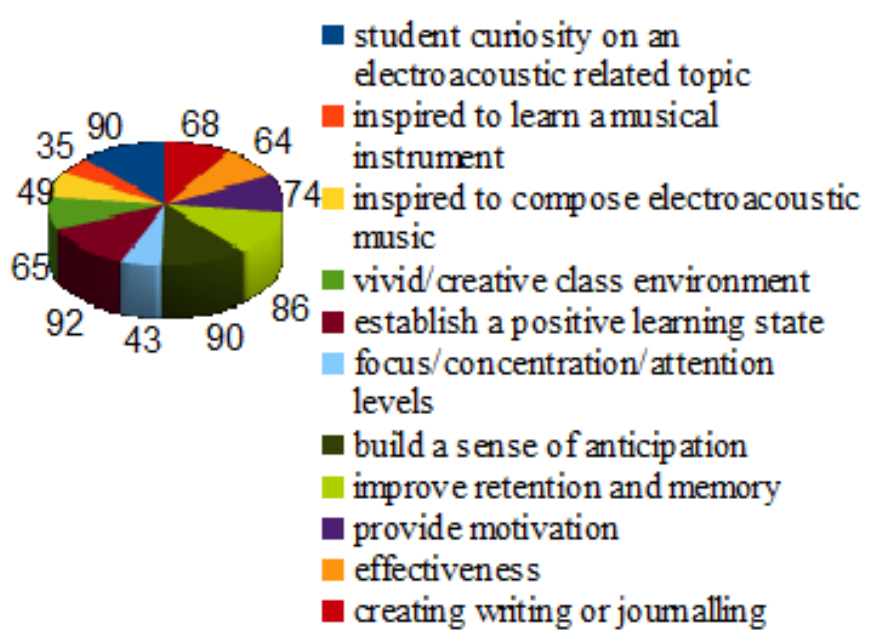

Fig 3:- Positive students' response percentages $(\%)$ on the effect of electroacoustic integration on their learning skills.

In order for educators to reinforce the integration's results and to create a rich and resonant classroom environment, they increased the following teaching methods (figure 4): providing background for project work, brainstorming and tests (by 40\%), greed and reward students (by $80 \%$ ), set a learning rhythm (by 50\%), create welcoming atmosphere (by 100\%), productivity (by 40\%), energise students during daily energy lulls (by 60\%), provide a stimulating sound break to increase attention (by 70\%), make exercise more fun (by 40\%) and encourage movement activities (by 30\%).

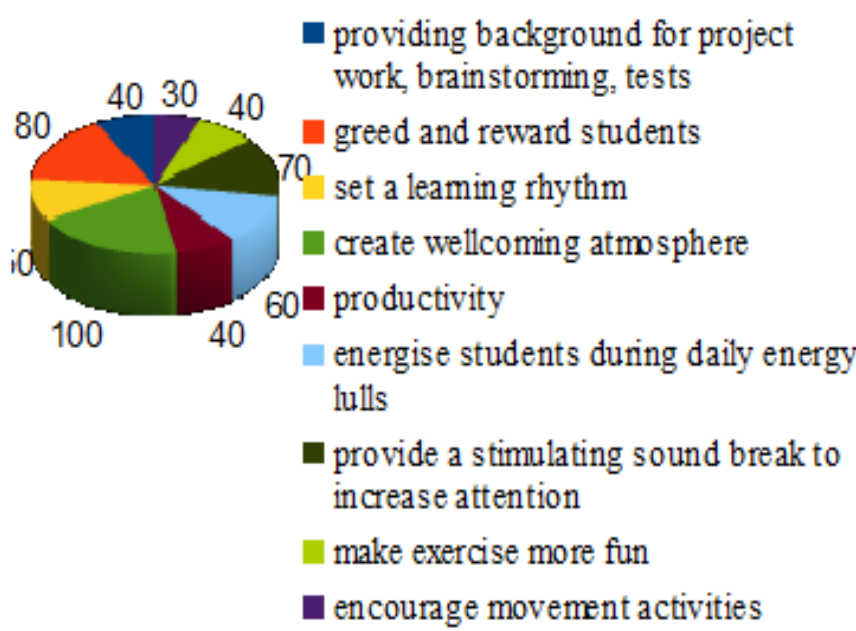

Fig 4:- Increase percentage $(\%)$ of teaching methods in electroacoustic integration.

Integrating electroacoustic music in classes, either as soundtrack music, or as a creative way of expressing and reflecting emotions, or even as pure musical theory and practice, activated information as a mental, physical and emotional knowledge, with positive effects in students' performance, motivation and memory. 


\section{CONCLUSIONS}

The integration of electroacoustic music in different school subjects has empirically proven to achieve a great enhancement in student learning, internal motivation, concentration and memory. It improved attention, attitude and class atmosphere, promoted personal expression, communication and interpersonal relationships inside and outside school, strengthened mental and physical wellbeing and prosperity. Students' enthusiasm and response would be a guideline and incentive for future ideas and uses of electroacoustic music in class. Research continues to be contacted to provide helpful guidelines for incorporating music into teaching and learning environments - applicable to all ages and educational settings.

Students who participated in the music education programmes learned to use electrocoustic music productively in their lives for their own benefit. They used electroacoustic music as a vehicle for interdisciplinary learning and creativity, emotional expression and socialisation. Research continues on the effect of electroacoustic music teaching on interpersonal relationships in intra-school and extra school environments. New educational programmes have been running since 2016 and onwards in Greek schools and further results are expected.

Marching on the 21st century, subject and course integration is an important educational method for achieving students' comprehensive and multifaceted knowledge. Furthermore, science and technology have become integral parts of music learning and creating, in the music curriculum as well. New musical styles, such as electroacoustic music, would eventually become fields of systematic scientific research, by bio-scientists and psychologists on their impact to human Knowledge, performance, productivity and stress levels. The effect of electroacoustic music to human well-being and prosperity wiil eventually be further explored and identified within the educational systems.

\section{ACKNOWLEDGMENT}

I would like to acknowledge and thank the many people who made these educational programmes possible. First, I would like to acknowledge the support of the standing Directorate of Secondary Education, Cultural Programmes Domain of Herakleion, Crete, which offered oversight for these programmes. Secondly, I would like to acknowledge that this paper was informed by the efforts of the many fellow educators, school principals and parents who shared their data, insights, ideas, enthusiasm, and expertise with the school psychologists and programmes' supervisor, responsible for analysing and organising the outcomes of the programmes. Special thanks should be granted to all students, who were tirelessly working, with dedication and enthusiasm, to accomplish the programmes' goals, often sacrificing enough of their after school time, as well as to all the parents/guardians for their support, understanding and open-mindness.

\section{REFERENCES}

[1]. Brewer, C. (1995). John Hopkin's Study: Integrating Music in the

Classroom.http://frequencyoflearning.com/johnhopkins-study integrating-music-in-the-classroom/ (cited in 2018)

[2]. Brewer, C. (1995). Music and Learning: Seven Ways to Use Music in the Classroom. Tequesta, Florida:LifeSounds.

[3]. Campbell, D. (2001). The Mozart Effect: Tapping the Power of Music to Heal the Body, Strengthen the Mind, and Unlock the Creative Spirit. Quill. An Imprint of Harper Collins Publishers.

[4]. DeMoss, K. \& Morris, T. (2002). How arts integration supports student learning: Students shed light on the connections. Chicago, IL: Chicago Arts Partnerships in Education (CAPE).

[5]. Lazanov,G. (1960). Accelerated Learning. https://www.learningdoorway.com/georgilozanov.htm 1 (sited in 2019).

[6]. National Academies of Sciences, Engineering, and Medicine. (2018). The Integration of the Humanities and Arts with Sciences, Engineering, and Medicine in Higher Education: Branches from the Same Tree. Washington, DC: The National Academies Press. https://doi.org/10.17226/24988.

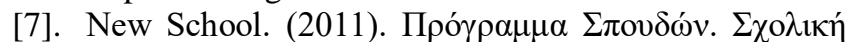

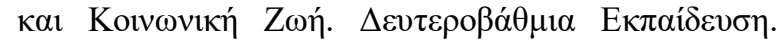

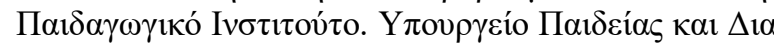

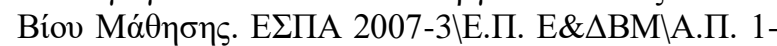

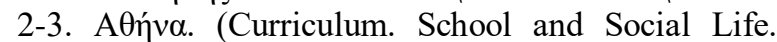
Secondary education. Pedagogical Institute. Ministry of Education and Lifelong Learning. NSRF 2007- $3 \backslash$ OP E \& $\Delta$ BM \A.П. 1-2-3. Athena).

\section{APPENDIX}

List of electroacoustic compositions used in the integrated classes.

$>$ Adkins, M. (2011). Road Side Picnic. https://mrmrecordings.bandcamp.com/album/anabandoned-landscape

$>$ Andrean, J. (2011). Maledetta. https://electrocd.com/en/album/5846/James_Andean/Ass emblance

$>$ Bayle, F. (1979-80). Toupie Dans Le Ciel (New Version 2009).

https://www.youtube.com/watch?v=tyCfJbJ8ZSI

$>$ Berezan, D. (2014). Lightvessels. https://electrocd.com/en/album/5847/David_Berezan/Cy cle_nautique

$>$ Berio, L. (1960). Momenti. https://www.youtube.com/watch?v=ZfZqD2iqxJ0

$>$ Boulez, P. (1985). Dialogue de l'ombre double. https://www.youtube.com/watch?v=tRALrBqln8s

$>$ Boura, V. (2001). Rhetoric Cue. https://sites.google.com/site/vboura/

$>$ Brummer, L. (1993) The Gates of H. in Stimmen Klange, ICMC '95 digital playground, DegeM. 
Cage, J. (1952). 4'33".

https://www.youtube.com/watch?v=JTEFKFiXSx4

$>$ Cage, J. (1939). Imaginary Landscape No.1. https://www.youtube.com/watch?v=p-3iLnXV90s

$>$ Chasalow, E. (1988) Fast Forward for Tape and Percussion in Over the Edge, New World Records, 80440-2.

$>$ Chion, M. (2014). Les vers luisants. https://www.youtube.com/watch?v=QOZEoyS5knw

$>$ Daoust, Y. (2005). About Time. https://electrocd.com/en/album/2430/Yves_Daoust/Voix

$>$ Delafontaine, S. (2013). Respire marche pars va-ten.https://electrocd.com/en/album/5917/Sophie_Delafon taine/Accord_ouvert

$>$ Dhomont, F. (1989) Artifices in The Human Touch, ICMC '94 International Computer Music Conference 1994 Denmark.

$>$ Dodge, C. (1980) Any Resemblance is Purely Coincidental in Computer Music Currents 11, wergo, WER 2031-2.

$>$ Eimert, H. (1962). Epitaph for Aikichi Kuboyama, for speakerelectronics.

https://www.allmusic.com/album/herbert-eimertepitaph-f\%C3\%BCr-aikichi-kuboyama-sechs-studienmw0001438362

> Harrison, J. (2014). Espaces caches. https://electrocd.com/en/album/5678/Jonty_Harrison/Vo yages

$>$ Henry, P. (1953). Antiphony. https://www.youtube.com/watch?v=km_MpzVtQXk

$>$ Jean, M. (2009). Out of Joint. https://electrocd.com/en/album/5659/Monique_Jean/Tro ubles

$>$ Justel, E. (2001). La radio, ?a d?tend . https://electrocd.com/en/album/5926/Elsa_Justel/Yegl

$>$ Koonce, P. (1996) Pins in Walkabout or Back, Electroacoustic Works, Mode:90

$>$ Landy, L. (2006-07). Oh 1? la radio. https://electrocd.com/en/album/3482/Various_artists/Bo uquet_of_Sounds

$>$ Lansky, P. (1978-79) "Six Fantasies on a Poem by Thomas Campion" in Fantasies and Tableaux, CRI, CD 683.

$>$ Malt, M. (2008). Cinqui?me Contemplation. https://www.youtube.com/watch?v=idLEjmi739c

$>$ Messiaen, O. (1937). F?te des belles eaux. https://www.youtube.com/watch?v=nrYgm5MML58

$>$ Moore, A. (2013). The Battle. https://electrocd.com/en/album/5268/Adrian_Moore/S\% C3\%A9quences_et_tropes

$>$ Nono, L. (1988-89). La Lontananza Nostalgica Utopica Futura. https://www.youtube.com/watch?v=X-CKVm8MXxU

Normandeau, R. (2005-06). Kuppel. https://electrocd.com/en/album/5274/Robert_Normandea $\mathrm{u} / \mathrm{D} \% \mathrm{C} 3 \% \mathrm{~B} 4 \mathrm{mes}$
Parmegiani, B. (1975). De Natura Sonorum. https://www.youtube.com/watch?v=c_JHjUFfOs8

$>$ Parmerud, A. (1994-95). Grains of Voices. https://electrocd.com/en/album/5840/\%C3\%85ke_Parme rud/Grains

$>$ Reich, S. (1966). Different Trains (Europe, During the war). https://www.youtube.com/watchv=pZRBfRXJyak

$>$ Risset, J.C. (1969) Mutations in Ohm: the early gurus of electronic music, Thomas Ziegler and Jason Gross.

$>$ Roy, S. (2008). Les territoires secrets. https://electrocd.com/en/album/6045/St\%C3\%A9phane_ Roy/L_inaudible

$>$ Schaeffer, P. (1948) Etude aux Chemins der Fer in Ohm: the early gurus of electronic music, Thomas Ziegler and Jason Gross.

$>$ Smalley, D. (1987) Wind Chimes in Computer Music Currents 5, wergo, wer 2025-2.

$>$ Stanovic, A. (2015). Foundry Flux. https://electrocd.com/en/album/5925/Adam_Stanovi\%C 4\%87/T\%C3\%A9n\%C3\%A9brisme

$>$ Stockhausen, K. (1959-60) Kontakte in Ohm: the early gurus of electronic music, Thomas Ziegler and Jason Gross.

$>$ Thome, D. (1994) Masks of Eternity in Palaces of Memory Electro-Acoustic Music Centaur, CRC2229.

$>$ Truax, B. (2009-13). The Elements and Beyond (Chalice Well, 2009., Fire Spirits, 2010., Aeolian Voices, 2013., Earth and Steal, 2013., From the Unseen World,2012).https://electrocd.com/en/album/5464/Barry _Truax/The_Elements_and_Beyond

$>$ Tudor, D. (1968) Rainforest Version 1 in Ohm: the early gurus of electronic music, Thomas Ziegler and Jason Gross.

$>$ Varese, E. (1958) Poem Electronique in Ohm: the early gurus of electronic music, Thomas Ziegler and Jason Gross.

$>$ Vinao, A. (1989/90) Tumblers in Der Prix ars electronica 92, Prix ars electronica 92.

$>$ Wishart, T. (1986) VOX-5 in Computer Music Currents 4, wergo, WER 2024-50.

$>$ Xenakis, I. (1970) Hibiki-Hana-Ma in Ohm: the early gurus of electronic music, Thomas Ziegler and Jason Gross. 